\title{
Polymorphism of Lymphocyte Function-associated Antigen-1 Demonstrated by a Lupus Patient's Alloantiserum
}

\author{
Ken D. Pischel, Steve D. Marlin, Timothy A. Springer, Virgil L. Woods, Jr., and Harry G. Bluestein \\ Division of Rheumatology, Department of Medicine, University of California Medical Center, San Diego, California 92103 ; \\ Dana Farber Cancer Institute, Harvard Medical School, Boston, Massachusetts 02115
}

\begin{abstract}
We have found a human serum, E27, obtained from a multiply transfused patient with systemic lupus erythematosus, which immunoprecipitates the lymphocyte function associated antigen1 (LFA-1). The immunoprecipitated molecules were identified as the LFA-1 alpha and beta chains by their comigration on SDS-PAGE, two-dimensional SDS-PAGE, and by sequential clearance experiments. Serum E27 did not immunoprecipitate LFA-1 from autologous cells, though LFA-1 molecules were present. In contrast, serum E27 immunoprecipitated LFA-1 from most but not all normal donor lymphocytes. Thus, serum E27 defines two serological phenotypes of LFA-1. 95\% of normal individuals tested exhibited the LFA-1 phenotype precipitated by serum E27. Serum E27 appears to be directed at determinants of the LFA-1 $\alpha$-chain and not the $\beta$-chain since it immunoprecipitated LFA-1 molecules but not the Mac-1 molecules. Additional evidence for the alpha chain specificity was provided by immunoprecipitation of mouse-human heterohybridoma cells. LFA-1 was immunoprecipitated by serum E27 from mouse-human heterohybridoma cells expressing the human $\alpha$-chain, not from a hybrid cell line expressing the human $\beta$-chain. Together these findings demonstrate an antigenic polymorphism of the human LFA-1 $\boldsymbol{\alpha}$-chain molecule.
\end{abstract}

\section{Introduction}

The lymphocyte function associated antigen-1 (LFA-1) ${ }^{1}$ molecules are cell surface glycoproteins important in leukocyte adhesion processes. They are heterodimers comprised of an $\alpha$-polypeptide chain of $177,000 \mathrm{~mol} w \mathrm{wt}$ and a $\beta$-polypeptide chain of $95,000 \mathrm{~mol} \mathrm{wt}$, noncovalently linked together (1). LFA-1 is one of a family of structurally similar molecules that also includes p150,95, and Mac-1 (the complement receptor CR3). Mac-1 is recognized by monoclonal antibodies (MAbs) Mac-1, Mo1, and OKM1, and is composed of a distinct $\alpha$-chain of $165,000 \mathrm{~mol}$ wt associated with a 95,000-mol wt $\beta$-subunit. The LFA-1 and Mac- $1 \beta$-subunits are apparently identical as indicated by identical isoelectric focusing patterns (2) and identical peptide maps

Address reprint requests to Dr. Pischel.

Received for publication 27 October 1986 and in revised form 17 February 1987.

1. Abbreviations used in this paper: LFA-1, leukocyte function associated antigen-1; MAb, monoclonal antibody; NW, nylon wool; SLE, systemic lupus erythematosus; 2D-PAGE, two-dimensional gel electrophoresis; 2-ME, 2-mercaptoethanol.

J. Clin. Invest.

(c) The American Society for Clinical Investigation, Inc.

$0021-9738 / 87 / 06 / 1607 / 08 \quad \$ 1.00$

Volume 79, June 1987, 1607-1614
$(3,4)$. The LFA-1, Mac-1 family also contains a third heterodimer, p150,95 composed of a distinct $150,000 \mathrm{~mol}$ wt $\alpha$-chain linked with the common 95,000-mol-wt $\beta$-chain. The members of this family are all heterodimers sharing a common $\beta$-chain complexed with a unique $\alpha$-subunits distinguished by size, isoelectric focusing point, and peptide patterns (2).

The LFA-1 molecules are expressed on the surface of lymphocytes, thymocytes, monocytes, granulocytes, and bone marrow cells (5). The Mac-1 molecules are present on human monocytes, granulocytes, and natural killer cells, but are absent (or minimally present) on lymphocytes. The p150,95 heterodimer has been less well characterized but it appears to be recognized by the MAb Leu M5 and is present upon monocytes and, in low density, on granulocytes and large granular lymphocytes.

Little structural variability of any of these molecules has been described in man. Recently, a polymorphism of the CR3 complement receptor that binds $\mathrm{C} 3$ bi has been reported (6). A murine MAb was found to immunoprecipitate CR3 from $14 \%$ of individuals. That MAb did not react with LFA-1 and was thought to react with an epitope on the Mac- $1 \alpha$-chain.

No structural variation of the human LFA-1 molecules has been previously reported. We have identified a human serum, obtained from a patient with systemic lupus erythematosus who had previously received multiple blood transfusions, that immunoprecipitates LFA-1 from lymphocytes of most but not all individuals. This serum appears to identify a phenotypic variation of the human LFA-1 molecules.

\section{Methods}

Cells and lymphocyte preparations. Peripheral blood mononuclear cells (PBMs) were obtained by Ficoll-Hypaque (Pharmacia Fine Chemicals, Piscataway, NJ) density gradient centrifugation (7), pelleted, and washed thrice with RPMI. These cells were either used directly or further processed by passage through a nylon wool (NW) column (8) to yield NW $T$-enriched cells ( $T$ cells) before iodination.

Mouse $\times$ human heterohybridoma cells expressing LFA-1 hybrid molecules have been previously described (9). Human PHA blasts, obtained from the parent of a LFA-1 Mac-1 deficient patient and the murine cell line BW5147 were fused and hybrids selected for the expression of human $\alpha$ - or human $\beta$-chains by flow cytometry. The MB $\times \mathrm{BW}^{+}$cells retain the human chromosome 16 and express hybrid LFA-1 molecules composed of human $\alpha$-subunits associated with mouse $\beta$-subunits. The $\mathrm{MB} \times \mathrm{BW} 5^{-}$hybrids were derived from the $\mathrm{MB} \times \mathrm{BW} 5^{+}$but have lost the human chromosome 16 and no longer express the human LFA-1 $\alpha$ chain. The $\mathrm{MB} \beta 3^{+}$hybrids retain human chromosome 21 and express hybrid LFA-1 molecules composed of human $\beta$-chain with mouse $\alpha$ chains and the $\mathrm{MB} \beta 3^{-}$cells were derived from the $\mathrm{MB} \beta 3^{+}$cells but have lost the human chromosome 21 and no longer express the human $\beta$ chain (9).

Radiolabeling. Lymphocytes were surface iodinated with lactoperoxidase by a modification of the method of Baur et al. (10) as previously described (11). To $5 \times 10^{7}$ cells in $500 \mu \mathrm{l}$ PBS were added $1 \mathrm{mCi} \mathrm{Na}{ }^{125} \mathrm{I}$ 
(New England Nuclear, North Billerica, MA) and $10 \mu \mathrm{l}$ lactoperoxidase (Calbiochem-Behring Corp., San Diego, CA, grade, $100 \mathrm{IU} / \mathrm{ml}$ ) and 25 $\mu \mathrm{l}$ of $0.03 \% \mathrm{H}_{2} \mathrm{O}_{2}$. After $5 \mathrm{~min} 5 \mu \mathrm{l}$ of lactoperoxidase and $10 \mu \mathrm{l}$ of $0.03 \%$ $\mathrm{H}_{2} \mathrm{O}_{2}$ were added and at $10 \mathrm{~min} 10 \mu \mathrm{l}$ of $0.03 \% \mathrm{H}_{2} \mathrm{O}_{2}$ was added. After 15 min the reaction was stopped by the addition of cold RPMI, cells centrifuged and washed six times with media. Viability was $>95 \%$ before and after iodination as judged by trypan blue exclusion.

Antibodies. Serum E27 was obtained from a patient with systemic lupus erythematosus (SLE). The serum was heat inactivated at $56^{\circ} \mathrm{C}$ for $30 \mathrm{~min}$, aliquoted, and frozen at $-80^{\circ} \mathrm{C}$ until use. MAb TS1/22 and MAb TS1/18 are LFA-1 chain specific monoclonal antibodies previously described $(2,12)$ that are directed at $\alpha$-chain and $\beta$-chain determinants, respectively. The MAb OKM1, which recognizes an epitope on the Mac1 molecule, was purchased from Ortho Diagnostics (Raritan, NJ).

Extraction and immunoprecipitation. Surface iodinated cells were usually incubated with serum or MAb prior to the solubilization of the cell membrane with nonionic detergent. $50 \mu \mathrm{l}$ of serum or $1 \mu \mathrm{l}$ of MAb ascites were incubated with intact cells for $30 \mathrm{~min}$ at $4^{\circ} \mathrm{C}$ and the cells washed once with media. Cells were then lysed with Tris-buffered saline containing $0.5 \% \mathrm{NP}-40$ and immunoprecipitated as previously described (11). Briefly, lymphocytes were lysed by suspending cells in $0.15 \mathrm{M} \mathrm{NaCl}$, $0.01 \mathrm{M}$ Tris pH 7.4, 0.5\% NP-40 (TBS-NP-40) containing $0.05 \mathrm{mM} \mathrm{N}$ $\alpha$-p-tosyl-L-lysine choromethyl ketone (TLCK, Sigma Chemical Co., St. Louis, MO), $0.06 \mathrm{mM}$ L-1-tosylamide-2-ketone (TPCK, Sigma Chemical Co.) and $0.2 \mathrm{mM}$ phenylmethylsulfonylfluoride (PMSF, Sigma Chemical Co.). After incubation for $30 \mathrm{~min}$ at $4^{\circ} \mathrm{C}$, cellular lysates were ultracentrifuged at $100,000 \mathrm{~g}$ for $30 \mathrm{~min}$ at $4^{\circ} \mathrm{C}$ and aliquots were precleared by incubation with $100 \mu \mathrm{l}$ of $10 \%$ Sansorbin (Staphylococcus aureus lacking protein A, Calbiochem-Behring Corp.) or $50 \mu$ l of Sepharose 4B for 15 min followed by centrifugation (microfuge $B$, Beckman Instruments, Inc., Palo Alto, CA) for 4 min. The immune complexes were collected with $50 \mu$ of $10 \% S$. aureus Cowan's strain I (SAC) (Calbiochem-Behring Corp.), or with $10 \mu \mathrm{l}$ Sepharose-protein A, or with $10 \mu \mathrm{l}$ of affinity purified rabbit anti-mouse kappa chain conjugated to Sepharose 4B $(1 \mathrm{mg} / \mathrm{ml})$ according to the manufacturer's instructions (Pharmacia Fine Chemicals), pelleted and washed six times with TBS-NP-40.

Sodium dodecyl sulfate-polyacrylamide gel electrophoresis (SDS$P A G E$ ). Washed immunoprecipitates were eluted and denatured with $50 \mu \mathrm{l} 1 \% \mathrm{SDS}$ and $5 \% 2$-mercaptoethanol (2-ME) by heating at $100^{\circ} \mathrm{C}$ for 1-2 min and analyzed by 8 or 10\% Laemmli SDS-PAGE (13) along with ${ }^{14} \mathrm{C}$ molecular weight markers myosin $(200,000 \mathrm{~mol} \mathrm{wt})$, phosphorylase B $(92,000 \mathrm{~mol} \mathrm{wt})$, bovine serum albumin $(68,000 \mathrm{~mol} \mathrm{wt})$, ovalbumin (45,000 mol wt), chymotrypsin ( $25,000 \mathrm{~mol} \mathrm{wt})$, beta-lactoglobulin $(18,400 \mathrm{~mol} \mathrm{wt})$, and cytochrome $c(12,400 \mathrm{~mol} \mathrm{wt})$ (Bethesda Research Laboratories, Gaithersburg, MD). Gels were fixed in $10 \%$ acetic acid, $10 \%$ 2-isopropyl alcohol then dried and autoradiographed with prefogged XAR-5 film (Eastman Kodak, Rochester, NY) using an intensifying screen (Cronex Lighting-Plus, Dupont, Wilmington, DE) for 1-7 d at $-80^{\circ} \mathrm{C}$.

$O^{\prime}$ Farrell two-dimensional gel electrophoresis (2D-PAGE). 2D-PAGE was carried out after the method of O'Farrell (14) as previously described (11). Samples were eluted from the SAC or Sepharose immunoadsorbents by incubation with $8 \mathrm{M}$ urea, $5 \% 2-\mathrm{ME}$ for $60 \mathrm{~min}$ at $22^{\circ} \mathrm{C}$ and applied to prefocused $6 \%$ acrylamide tube gels with $10 \mathrm{mM}$ phosphoric acid (pH 3.9) and $50 \mathrm{mM}$ Tris base ( $\mathrm{pH} \mathrm{9.9)} \mathrm{electrode} \mathrm{solutions,} \mathrm{and} \mathrm{focused} \mathrm{for}$ $10 \mathrm{~h}$ at $1,000 \mathrm{~V}$. The gels were then equilibrated with SDS-PAGE diluent buffer and run on 8\% SDS-PAGE in the second dimension and fixed and processed as described above for one-dimensional SDS-PAGE.

\section{Results}

Serum E27 immunoprecipitates two polypeptides that co-electrophoresed with the LFA-1 $\alpha$ - and $\beta$-chains. In order to detect lymphocyte surface molecules reactive with the lupus serum E27, immunoprecipitation experiments were performed. NW purified $T$ cells were isolated, and their cell surface proteins were iodinated with lactoperoxidase and reacted with serum from lupus patient
E27. After detergent-solubilization, the iodinated surface molecules bound to antibody were immunoprecipitated and analyzed by SDS-PAGE (Fig. 1). Serum E27 immunoprecipitated two iodinated cell surface molecules whose molecular weights were estimated to be 175,000 and 95,000 (lane 5). In addition, nonspecific bands of 80,000 and $50,000 \mathrm{~mol} \mathrm{wt}$ are seen in the serum E27 precipitate and also in negative control samples (lanes 1 and 2). In some experiments serum E27 also precipitated chains of 43,000 and $12,000 \mathrm{~mol}$ wt which comigrated with HLA chains (data not shown). Because the two larger E27-immunoprecipitated molecules had similar molecular weights to the subunits of LFA-1, their electrophoretic migration was compared with that of immunoprecipitates produced by LFA-1 specific monoclonal antibodies TS1/22 and TS1/18 (Fig. 1, lanes 3 and 4). The 175,000-mol-wt band immunoprecipitated with E27 coelectrophoresed with the LFA-1 $\alpha$-chain and the 95,000-mol-wt band coelectrophoresed with the LFA-1 $\beta$-chain. This suggested that serum E27 contained antibody reactive with the LFA-1 molecules.

To more critically compare LFA-1 and the molecules precipitated with E27, they were analyzed by O'Farrell 2D-PAGE. Surface iodinated cells were reacted with serum E27 or LFA-1specific MAb and immunoprecipitates prepared. The samples were denatured with urea, reduced with $2-\mathrm{ME}$ and subjected to isoelectric focusing for $10 \mathrm{~h}$ followed by SDS-PAGE in the second

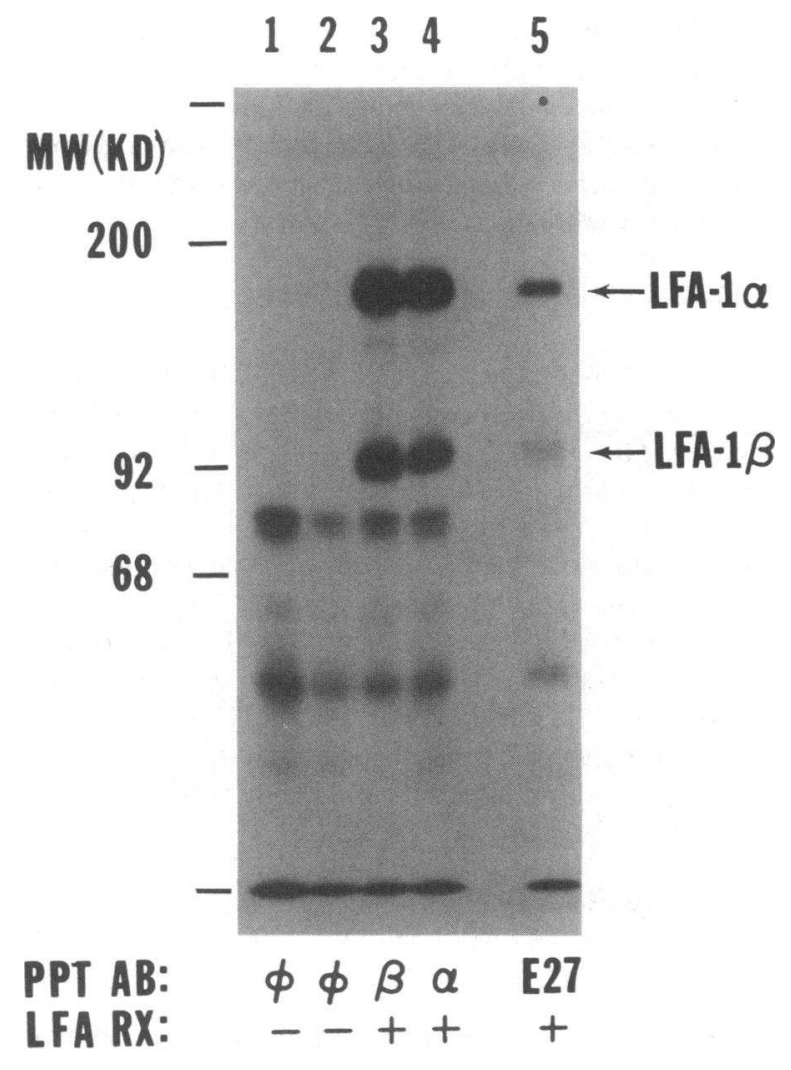

Figure 1. Comparison of lymphocyte surface antigens precipitated with human serum E27 and LFA-1 by SDS-PAGE. Radioiodinated lymphocytes were reacted with (lane 1) no Ab; (lane 2) control MAb; (lane 3) anti-LFA-1 $\alpha$-MAb TS1/22; (lane 4) anti-LFA- $\beta$ MAb TS1/ 18; and (lane 5) human serum E27 and immunoprecipitates prepared. Immunoprecipitates were reduced and run on $8 \%$ SDS-PAGE. Molecular weight markers are shown at left. 
dimension and autoradiography. The molecules immunoprecipitated by the patient's serum comigrated exactly with the LFA$1 \alpha$ - and $\beta$-chains precipitated with the LFA- 1 specific MAb (Fig. 2). Each of the 175,000-mol-wt chains focused between a $\mathrm{pH}$ range of 4.3 to 4.6 and each of the 94,000 -mol-wt chains focused at positions from $\mathrm{pH} 4.6$ to 5.0. This result strengthened the suggestion that serum E27 contained antibodies to the LFA1 molecules.

Preclearance of LFA-1 molecules removes $E 27$ reactive molecules. The identity of the molecules precipitated by E27 as LFA1 was confirmed by preclearance experiments. Aliquots of radioiodinated lymphocytes were first incubated with either MAb specific for the LFA-1 $\alpha$-chain, LFA- $1 \beta$-chain, or a control MAb, and then the Ab-complexed molecules were removed. Next, the precleared extracts were immunoprecipitated with serum E27 or LFA- 1 specific MAb and analyzed by SDS-PAGE. Clearance with MAb to LFA- $1 \alpha$ - or $\beta$-subunits resulted in the substantial removal of the LFA-1 molecules (Fig. 3, lanes 2, 3, 5, 6) and the nearly complete depletion of the 175,000 -mol-wt molecule normally immunoprecipitated by serum E27 (Fig. 3, lanes 8 and 9). Together the electrophoretic comigration of E27-precipitated molecules with LFA-1 subunits and clearance of E27 chains by LFA-1 MAb established the identity of the two E27 reactive molecules as the $\alpha$ - and $\beta$-chains of LFA- 1 .

Serum E27 is alloreactive and not autoreactive. Lupus patient E27, whose serum contained the anti-LFA-1 antibodies, had received numerous transfusions $10-20$ yr ago for severe recurrent hemolytic anemia. This raised the issue of whether the antiLFA-1 antibodies detected in her serum were a form of auto-

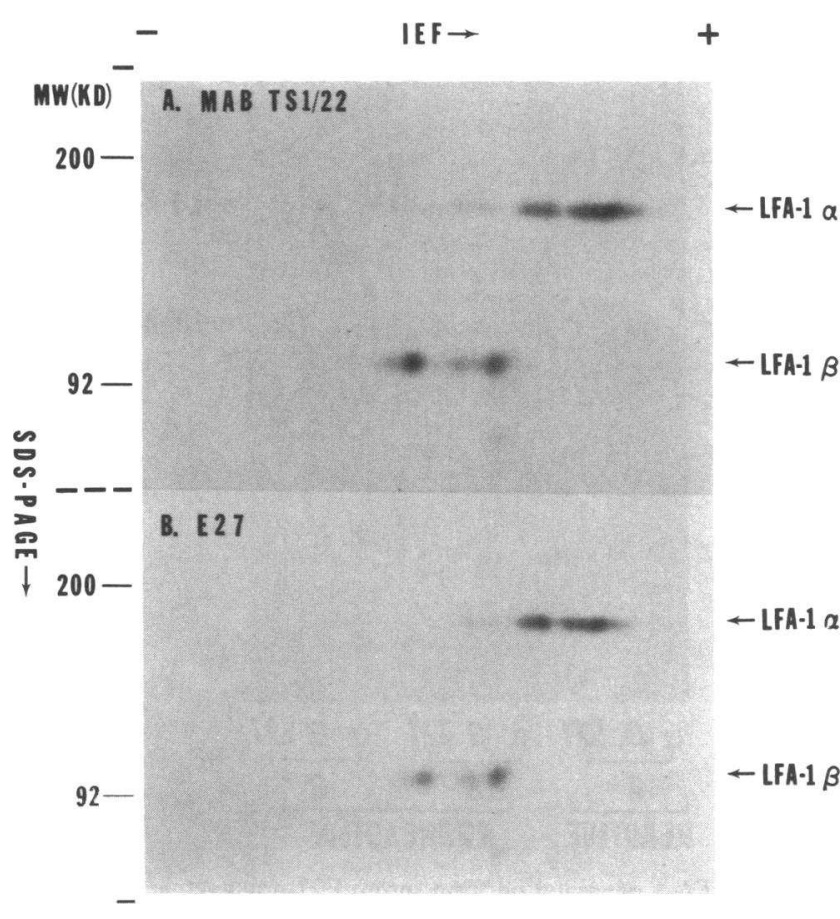

Figure 2. Comparison of E27-immunoprecipitated molecules and LFA-1 chains on O'Farrell two-dimensional gels. Radiolabeled lymphocytes were immunoprecipitated with anti-LFA- $1 \alpha$-specific MAb TS1/22 $(A)$ and serum E27 $(B)$; run on two dimensional O'Farrell gels and autoradiographed. Isoelectric focusing was first conducted from left to right followed by reduction with 2-ME and SDS-PAGE from top to bottom.

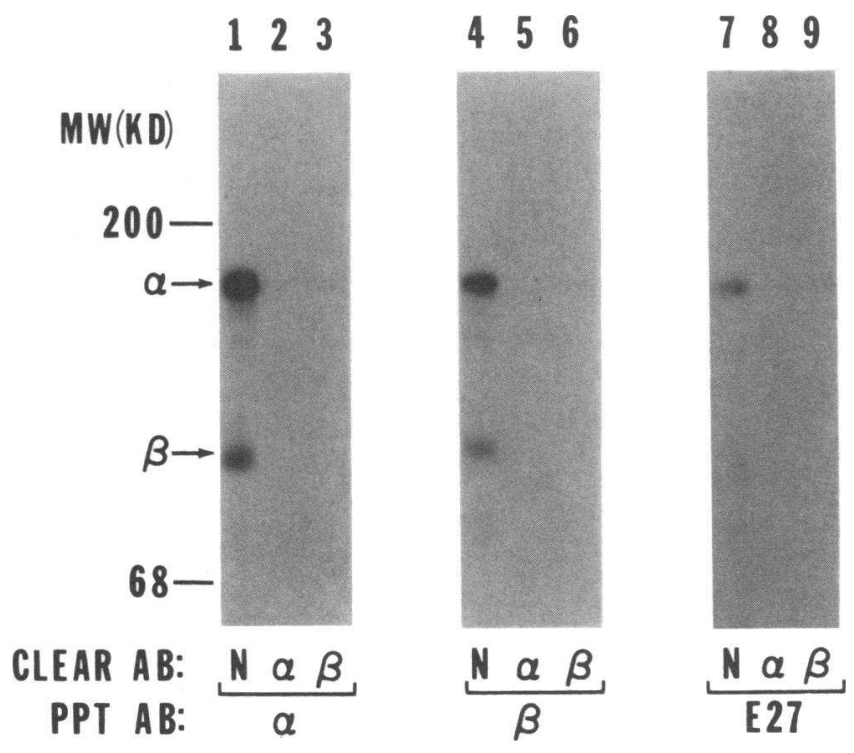

Figure 3. Sequential immunoprecipitation of LFA-1 and E27-reactive molecules. Radiolabeled lymphocyte lysates were aliquoted and samples precleared either with control MAb bound to Sepharose (lanes 1 , 4,7 ), anti-LFA-1 $\alpha$-MAb TS1/22 (lanes 2, 5, 8), or anti-LFA-1 $\beta$-MAb TS1/18 (lanes 3, 6, 9). Immunoprecipitates were then prepared from the precleared lysates with either the anti-LFA-1 $\alpha$ MAb TS1/22 (lanes 1-3), anti-LFA-1 $\beta$-MAb TS1/18 (lanes 4-6), or serum E27 (lanes 7-9) and run on reduced 7\% SDS-PAGE.

reactive antilymphocyte antibodies, such as are present in some lupus sera, or were alloreactive antilymphocyte antibodies. To test this, PBMs from the patient and a normal individual were isolated, radioiodinated, and reacted with serum E27. Immunoprecipitates from the patient and control individual were compared by SDS-PAGE (Fig. 4). Serum E27 was found to pre-

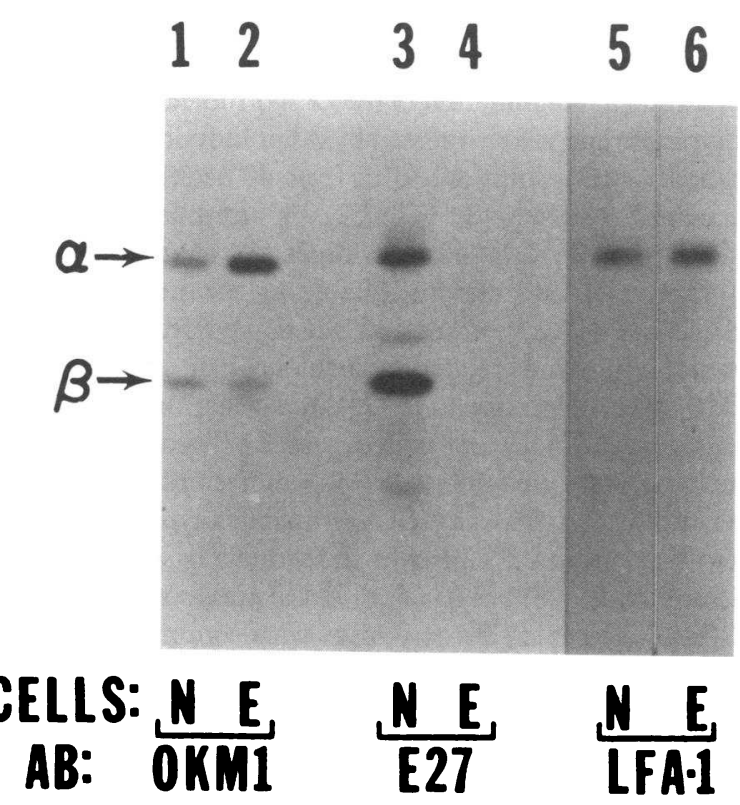

Figure 4. Test of autologous cells for LFA-1 reactivity with serum E27. Radiolabeled PBMs from lupus patient E27 $(E)$ and a healthy individual $(N)$ were immunoprecipitated with MAb OKM1 (lanes $l$ and 2), serum E27 (lanes 3 and 4) or the anti-LFA-1 MAb TS1/22 (lanes 5 and 6 ), reduced and run on 10\% SDS-PAGE and autoradiographed. 


\section{8}

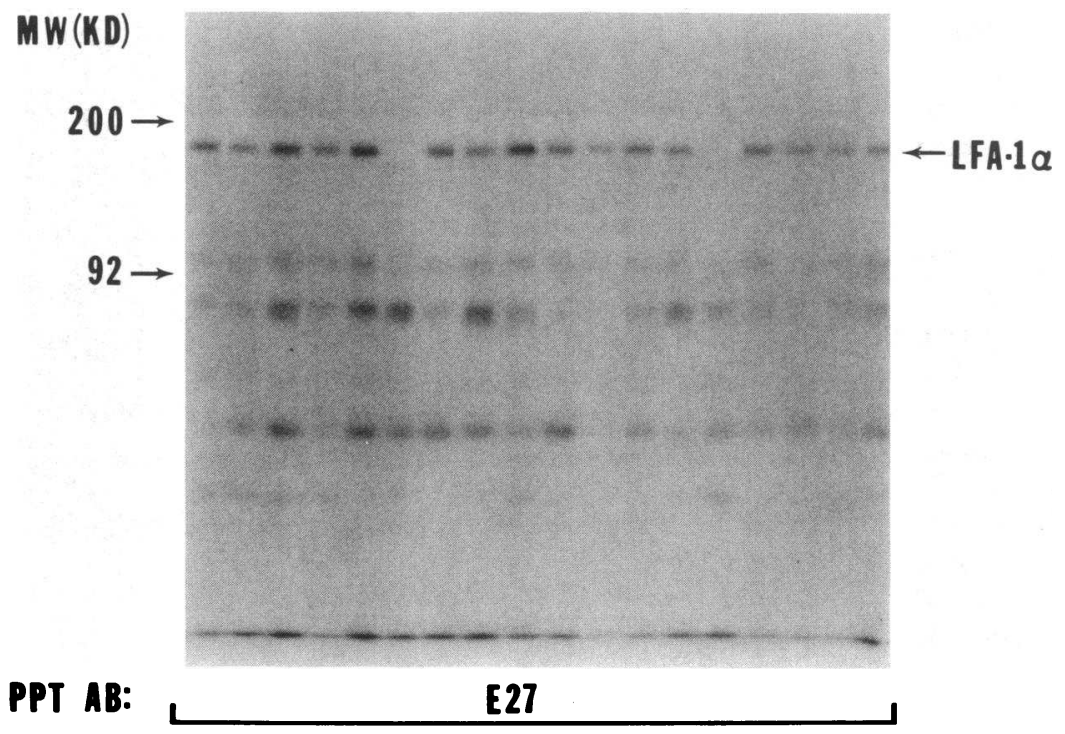

Figure 5. Screen of healthy individuals for the ability of serum E27 to precipitate LFA-1. Radiolabeled PBMs from 18 healthy individuals were immunoprecipitated with serum E27 and run on 10\% SDS-PAGE and autoradiographed. The position of the LFA-1 $\alpha$-chain is marked at the right. cipitate LFA-1 from the control cells (lane 3) but did not precipitate LFA-1 from autologous cells (lane 4). The LFA-1 family of molecules is present on the patient's cells as demonstrated by their immunoprecipitation by MAb to OKM1 (lane 2) and LFA1 (lane 6). Although the $\beta$-chain of LFA- 1 is not seen on this reproduction of the gel (lanes 5 and 6 ) it is present and more readily seen with longer exposure. Thus, it is clear that the lack of autoreactivity by E27 was not due to modulation of LFA-1 by autoantibodies or lack of expression of these molecules on E27's cells. The finding that serum E27 reacted with lymphocytes obtained from several donors but not with autologous LFA-1 molecules suggested the patient expressed a variant form of LFA-1.

LFA-1 phenotypic variation in the population. Patient E27 could manifest a rare mutation of the LFA-1 molecules or express an allotypic variant also expressed by other individuals. In order to test these two possibilities, PBMs from 40 healthy individuals were screened for reactivity with E27 by immunoprecipitation and SDS-PAGE. 2 of the 40 individuals (5\%) had no apparent LFA-1 molecules immunoprecipitable by serum E27 (Fig. 5, lanes 6 and 14). Since an immunodeficiency syndrome involving the absence of the three related molecules constituting the LFA1 family has been described (15-23), the cells from the two individuals who did not react with serum E27 were reexamined to determine if they expressed LFA-1 molecules on their cell surfaces. Both LFA- $1 \alpha$ - and LFA- $1 \beta$-chains could be immunoprecipitated from cells of both individuals by specific MAb (Fig. 6, lanes 4, 5, 7,8) but again, as in the previous experiment, their LFA-1 molecules did not react with serum E27 (Fig. 6, lanes 6,9 ). $5 \%$ of individuals from the normal population examined thus expressed a phenotypic variant of LFA-1 that does not react with serum E27.

Physicochemical properties of allotypic LFA-1 molecules. The size and charge characteristics of the LFA-1 molecules isolated from one of the nonreactive individuals were compared with those of the more common LFA-1 phenotype by O'Farrell 2DPAGE (Fig. 7). By this analysis the $\beta$-chain prepared from the E27-nonreactive individuals appeared to be identical to the
LFA-1 $\beta$-chain of the E27-reactive individuals. The positions of the $\alpha$-chains were also identical and although the more basic spots are fainter in this figure, other gels showed identical intensities as well as positions for the $\alpha$-chains. This result indicated

\section{$\begin{array}{lllllllll}1 & 2 & 3 & 4 & 5 & 6 & 7 & 8 & 9\end{array}$}

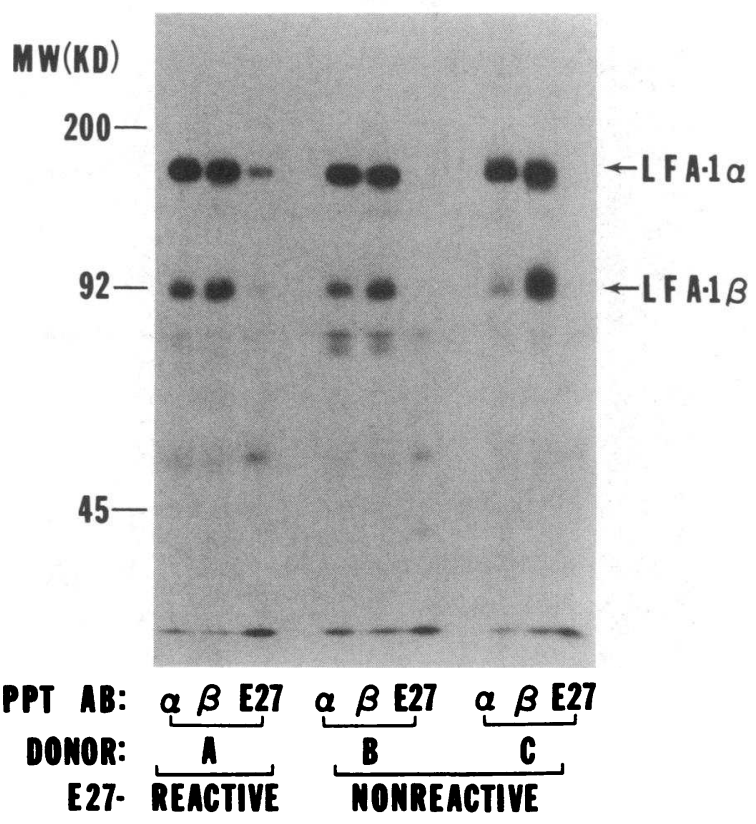

Figure 6. LFA-1 precipitation from serum E27-nonreactive individuals. Lymphocytes were prepared from individual A, previously shown to have LFA-1 precipitated by serum E27 (lanes 1-3), and individuals B (lanes 4-6) and C (lanes 7-9) previously shown not to have LFA-1 immunoprecipitated by serum E27. The cells were radioiodinated and immunoprecipitated either with MAb specific for LFA-1 $\alpha$-subunit (lanes $1,4,7$ ), LFA-1 $\beta$ subunit (lanes 2, 5, 8), or serum E27 (lanes 3, 6 , 9). Samples were reduced and run on $8 \%$ SDS-PAGE and autoradiographed. 


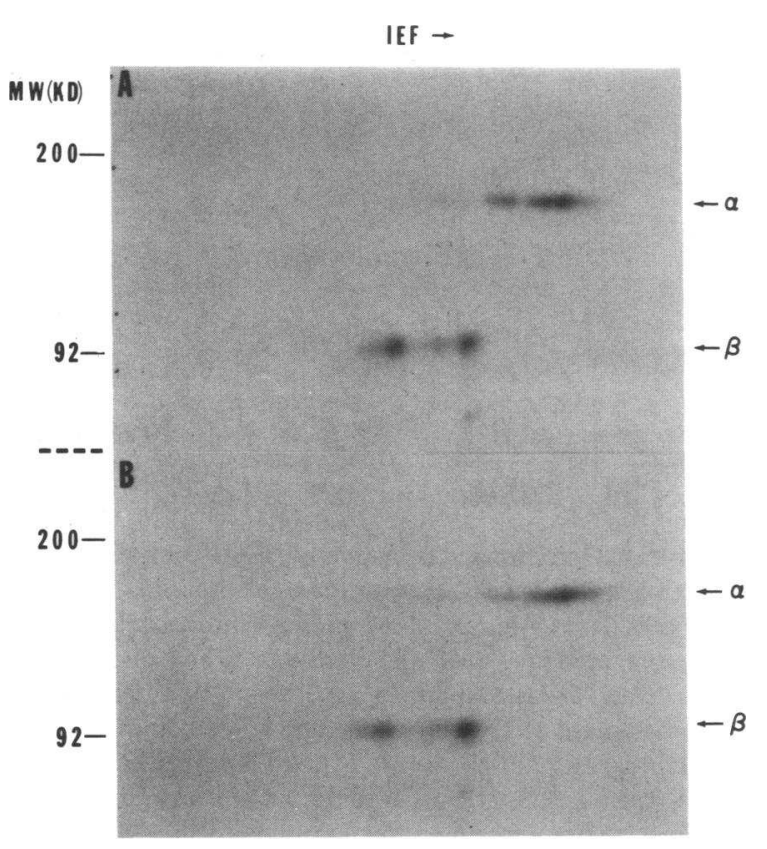

Figure 7. Comparison of LFA-1 molecules from E27-reactive and nonreactive individuals by two-dimensional gel electrophoresis. Lymphocytes were prepared from individual A, previously shown to have LFA-1 precipitated by serum E27, and individual B, previously shown not to have LFA-1 precipitated by serum E27. The cells were radioiodinated and LFA-1 immunoprecipitated from each with MAb TS1/22 and samples reduced and run on O'Farrell two-dimensional gels.

that large alterations of the $\alpha$ - or $\beta$-chain structures, such as a sizable peptide deletion or lack of carbohydrate do not exist. Instead, a minor difference of the LFA-1 chains, such as an amino acid substitution, which is not detectable by the method of O'Farrell 2D-PAGE analysis, probably accounts for the presence or absence of reactivity with serum E27.

Chain specificity of serum E27. It was of interest to determine the portion of the LFA-1 molecules recognized by serum E27 since those antibodies probably recognize the altered portion of the LFA-1 molecules. Various approaches have been used to determine this. First when LFA-1 molecules were precipitated by serum E27 and the intensity of the $\alpha$-chain band compared with that of the $\beta$-chain, several experiments demonstrated that the $\alpha$-chain band was more intense than the $\beta$-chain band (e.g., Fig. 1). This pattern of intensities is very similar to that produced by the LFA- $1 \alpha$-chain specific MAb TS1/22 and contrasts to the nearly even intensity of the $\alpha$ - and $\beta$-chains usually observed in immunoprecipitates produced with the LFA-1 $\beta$-chain specific MAb TS1/18.

A second approach to the identification of the chain recognized by serum E27 has been to prepare LFA-1 immunoprecipitates containing both the LFA- $1 \alpha$ - and $\beta$-chains and subjecting these immunoprecipitates to incubation conditions with various pHs to partially dissociate the LFA-1 subunits. Similar treatments have been used to partially denature and dissociate the $\alpha$ - and $\beta$-chains of LFA- 1 to show the preferential retention of one chain or the other depending upon the epitope specificity of the MAb (7). E27 and LFA-1 immunoprecipitates prepared from iodinated lymphocytes were treated for $30 \mathrm{~min}$ at $4^{\circ} \mathrm{C}$ with solutions composed of $0.5 \mathrm{M} \mathrm{NaCl}, 0.5 \% \mathrm{NP}-40,100 \mathrm{mM}$ diethylamine adjusted to $\mathrm{pH} 7.2,10.7,11.2$, or 11.5 , and then centrifuged and washed in NaCl-Tris-NP-40 solution (pH 8.0). The chains remaining bound to the antibody and Sepharose protein A were denatured and run on SDS-PAGE (Fig. 8). After treatment at $\mathrm{pH} 11.2$, complete disappearance of the LFA- $1 \beta$-chain and preferential retention of the $\alpha$-chains was observed. Since after treatments with $\mathrm{pH} 11.2$ and 11.5 the E27 antibody-precipitate partially retained the LFA- $1 \alpha$-chain without any apparent $\beta$ chain present (even upon prolonged film exposures) the antiLFA-1 reactivity observed is likely specific to the $\alpha$-chain itself and not directed towards either the $\beta$-chain or an $\alpha-\beta$ combinatorial determinant. When LFA-1 samples immunoprecipitated with the $\beta$-chain specific MAb TS1/18 were treated with $\mathrm{pH}$ 11.2 both the $\alpha$ - and $\beta$-chain completely disappeared (data not shown). Thus, the pattern of $\alpha$-chain retention observed with E27 is not the result of nonspecific retention of the $\alpha$-chain.

Additional evidence supporting the $\alpha$-chain specificity of the E27 serum comes from immunoprecipitation experiments using other cell types. In extracts of PBMs there exists a mixture of LFA-1 molecules with Mac-1 molecules. If the E27 antibodies were specific for the $\beta$-chain, the immunoprecipitates would be predicted to contain two types of $\alpha$-chains. This was examined by preparing peripheral blood mononuclear cells containing lymphocytes and monocytes, radioiodinating them and im-

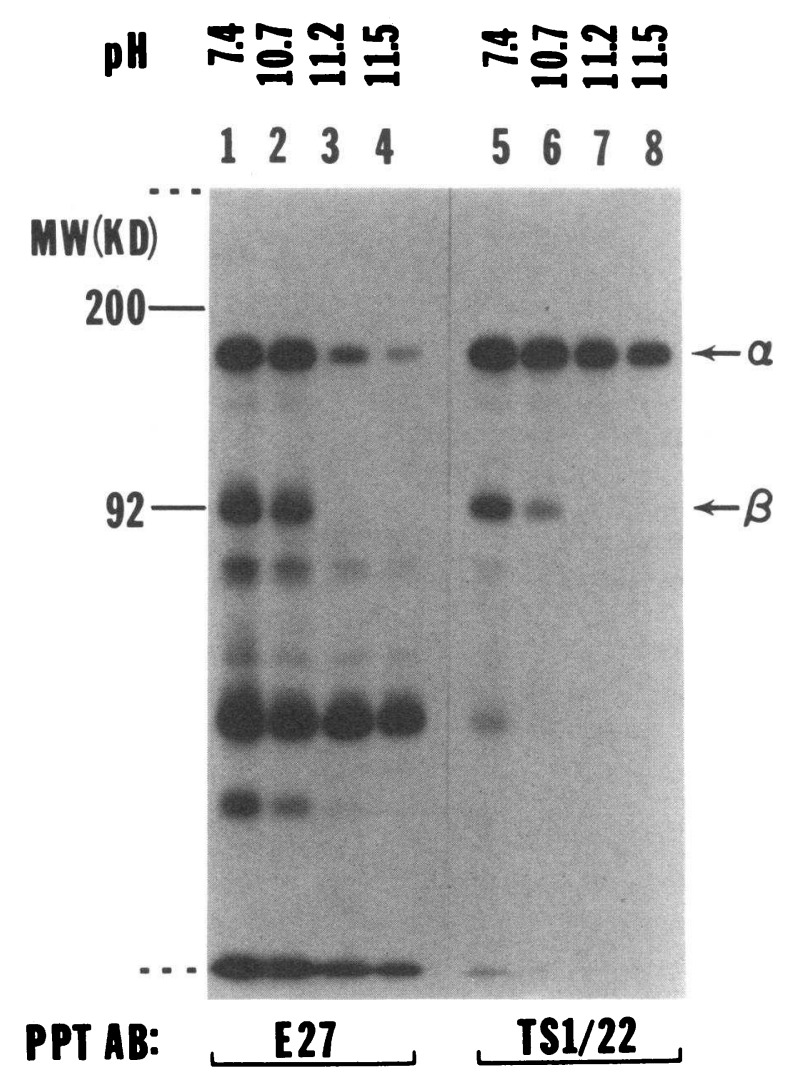

Figure 8. Dissociation of E27- and TS1/22-bound LFA-1 chains. Radiolabeled LFA-1 was immunoprecipitated with serum E27 (lanes 14 ) and MAb TS1/22 specific for LFA-1 $\alpha$-chain (lanes 5-8). The Sepharose-antibody-LFA-1 samples were treated with solutions of $0.5 \mathrm{M}$ $\mathrm{NaCl}, 0.5 \% \mathrm{NP}-40,100 \mathrm{mM}$ diethylamine adjusted to $\mathrm{pH} 7.4$, (lanes 1 and 4), pH 10.7 (lanes 2 and 6), $\mathrm{pH} 11.2$ (lanes 3 and 7), and $\mathrm{pH} 11.5$ (lanes 4 and 8 ) for $30 \mathrm{~min}$ at $4^{\circ} \mathrm{C}$, centrifuged and washed once in $\mathrm{NaCl}-\mathrm{Tris}-\mathrm{NP}-40$ (pH 7.4) and analyzed by $8 \%$ SDS-PAGE (lanes 2 and 6). 
munoprecipitating with MAb to either the LFA-1 $\alpha$-chain (Fig. 9, lane 1 ) or $\beta$-chain (lane 2), or with serum E27 (lane 3). The immunoprecipitates were run on a $6 \%$ SDS-PAGE gel capable of separating the Mac- 1 (OKM1) $\alpha$-chain $(165,000 \mathrm{~mol} \mathrm{wt})$ from the LFA-1 $\alpha$-chain $(177,000 \mathrm{~mol} w \mathrm{w})$. LFA-1 $\beta$-chain specific MAb TS1/18 immunoprecipitated both of those $\alpha$-chains, but serum E27, like the $\alpha$-chain specific MAb TS1/22 only precipitated the LFA-1 and not the Mac-1 $\alpha$-chain. This supports the contention that E27 reacts with the LFA-1 $\alpha$-chain and not the shared $\beta$-chain.

Analysis of the LFA-1 chain specificity of serum E27 using heterohybridoma cells. Mouse $\times$ Human heterohybridoma cells have been developed that retain the human chromosomes coding for either the human $\alpha$ - or human $\beta$-chain of LFA-1 (9). One of those lines $\left(\mathrm{MB} \times \mathrm{BW}^{+}\right)$expresses hybrid LFA-1 molecules composed of human $\alpha$-subunit associated with murine $\beta$-chain. Another line $\left(\mathrm{MB} \beta 3^{+}\right)$expresses human LFA- $1 \beta$-chain in association with murine $\alpha$-chain, and does not express human $\alpha$ chains. Sublines $\mathrm{MB} \times \mathrm{BW}^{-}$and $\mathrm{MB} \beta 3^{-}$were derived from these two lines and have lost the previously retained human chromosomes and no longer express the human LFA- $1 \alpha$-or $\beta$-chains, respectively. These cell lines were surface radioiodinated and reacted with serum E27 or with MAbs TS1/18, or TS1/22, and immunoprecipitates prepared and run on SDS-PAGE. As expected, human LFA- $1 \alpha$ - and $\beta$-chains were immunoprecipitated from human phytohemagglutinin (PHA) blast cells (Fig. 10, lanes

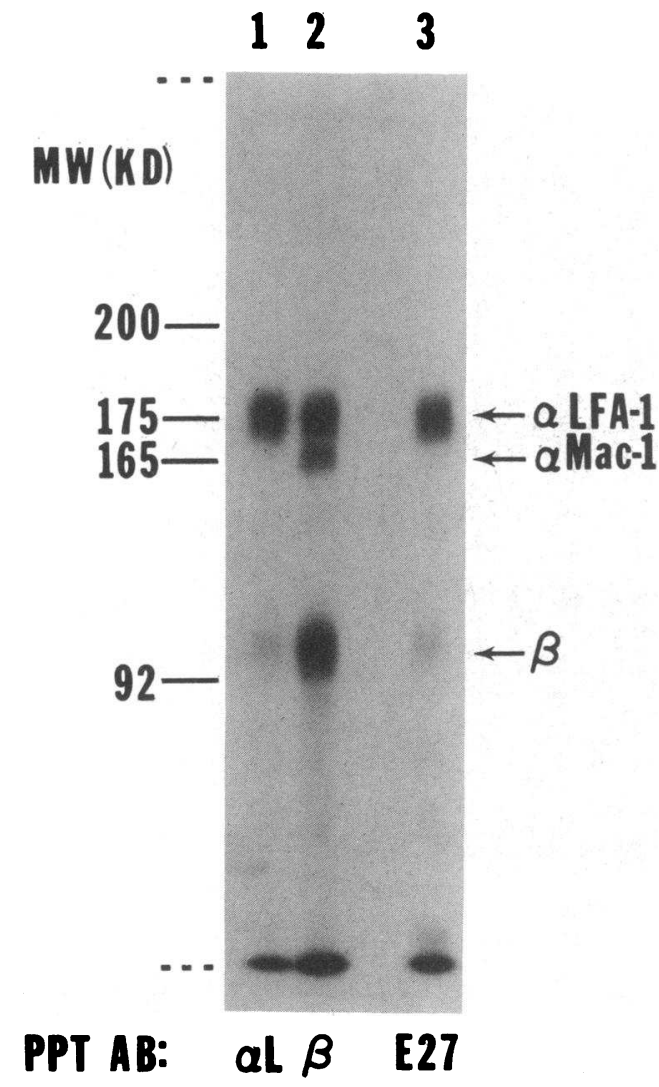

Figure 9. Analysis of alpha chains immunoprecipitated from PBMs by serum E27. Radiolabeled PBMs were immunoprecipitated with either anti-LFA-1 $\alpha$ MAb TS1/22 (lane 1), anti-LFA-1 $\beta$ MAb TS1/22 (lane 2 ), or serum E27 (lane 3) and run on low percent (6\%) SDS-PAGE and autoradiographed.
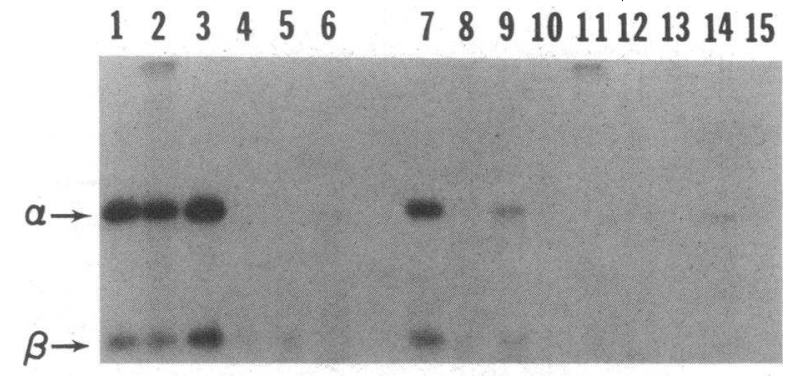

\section{PPT AB: $\alpha \beta E \alpha \beta E$ \\ CELLS: PHA BW5147

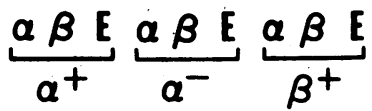

Figure 10. Serum E27 immunoprecipitation of LFA-1 from mouse $\times$ human heterohybridoma cells. Human PHA cells (lanes 1-3), murine BW5147 cells (lanes 4-6), and three mouse $\times$ human heterohybridoma cell types: human $\alpha+-\mathrm{MB} \times \mathrm{B5}^{+}$(lanes 7-9), human $\alpha$-negative $\mathrm{MB} \times \mathrm{B5}^{-}$(lanes 10-12), and human $\beta$-positive $\mathrm{MB} \beta 3^{+}$(lanes 13$15)$, were radioiodinated and reacted with either MAb to human LFA$1 \alpha$-chain (TS1/22, lanes $1,4,7,10,13$ ), MAb to human LFA-1 $\beta$ chain (TS1/18, lanes $2,5,8,11,15$ ), or serum E27 (lanes 3, 6, 9, 12, 15). Immunoprecipitates were prepared and run on reduced $8 \%$ SDSPAGE and autoradiographed.

1-3), but no LFA-1 was immunoprecipitated from the BW5147 mouse cells (lanes 4-6). The human $\alpha$-chain specific MAb TS1/ 22 precipitated LFA-1 from the human $\alpha^{+}$-hybrid (MB $\times \mathrm{BW}^{+}$, lane 7) but none was seen with the derivative human LFA-1 $\alpha$ negative $\left(\mathrm{MB} \times \mathrm{BW}^{-}\right)$cells (lane 10$)$ or from the human $\beta^{+}$. hybrid (lane 13 ). The $\beta$-chain specific MAb TS1/18 precipitated a detectable LFA- $1 \alpha$-chain from the human LFA-1 $\beta$-positive cells $\left(\mathrm{MB} \beta 3^{+}\right.$, lane 14$)$ and a less intense $\beta$-chain (seen more clearly on a longer exposure). MAb TS1/18 did not precipitate LFA-1 from the human $\alpha^{+}$-hybrid (lane 8 ) or from the human LFA- $1 \beta$-negative ( $\mathrm{MB} \beta 3^{-}$cell line, data not shown). These results are consistent with previous observations and indicate the cells were expressing the LFA-1 subunits in the anticipated fashion.

Serum E27 precipitated LFA-1 from the human LFA-1 $\alpha$ chain positive cells $\left(\mathrm{MB} \times \mathrm{BW5}^{+}\right.$, lane 9), but not from the derivative human $\alpha$-negative ( $\mathrm{MB} \times \mathrm{BW} 5^{-}$cells, lane 12). Furthermore serum E27 did not precipitate LFA-1 from the human $\beta$-positive hybrid cells (MB $\beta 3^{+}$, lane 15$)$. The serum E27 antiLFA- 1 reactivity thus is related to determinants present upon the human $\alpha$-chain.

\section{Discussion}

We have identified two phenotypes of the human LFA-1 molecules by a differential ability to react or not react with serum E27. This serum immunoprecipitates LFA-1 from most individuals (95\% of those tested). Its reactivity with an epitope on the LFA- $1 \alpha$-chain has been supported by several lines of evidence: preferential $\alpha$-chain immunoprecipitation; lack of reactivity with Mac-1; dissociation experiments showing preferential retention of the $\alpha$-chain; and most convincingly by experiments showing precipitation from mouse $\times$ human hybrids expressing human LFA-1 $\alpha$-chain and not with hybrids expressing human LFA-1 $\beta$-chain. Since the immune reactive epitope should coincide with the site of allotypic variation, the LFA-1 variability detected by this serum most likely resides in the $\alpha$-chain. 
Attempts to show that E27 reacts with dissociated LFA- $\alpha$ chains using the technique of Western blotting have been unsuccessful (data not shown). The lack of reactivity with dissociated LFA-1 $\alpha$-chain on the blots might indicate that the immunoreactive sites are perturbed by the conditions used, or that they are dependent upon $\alpha$ - and $\beta$-chain interactions for their immunoreactive conformation. Since human $\alpha$ - and mouse $\beta$ chains were precipitated from the human $\alpha$-chain bearing human $X$ mouse heterohybridoma cells, any chain interactions necessary for the molecule's antigenicity are not apparently influenced by substitution with murine $\beta$-chain. The most likely explanation for the failure of E27 to immunoblot to dissociated LFA-1 chains is that the blotting conditions alter the antigenic site on the $\alpha$ chains. Studies of some LFA-1 specific monoclonal antibodies have revealed similar difficulties in blotting (Marlin, S. D., and T. A. Springer, personal observation).

To the best of our knowledge this is the first description of an antigenic variation of the human LFA-1 molecules. However, an allotypic variation of murine LFA-1 has been described (4). The E27-reactive epitope is distinct from the TS1/22-reactive epitope of LFA-1 since the MAb recognized both forms of the LFA-1 molecules. No other anti-LFA-1 MAb have been shown to react with only a subset of human LFA-1 molecules. If as suspected, the difference between the two phenotypes of LFA1 molecules arises from alteration of the $\alpha$-chain structure, this could be the result of amino acid substitutions, multiple amino acid changes or various postranslational modifications. As indicated by the identical two-dimensional O'Farrell gel electrophoresis patterns of the normal and variant LFA- $1 \alpha$-chains, the variations do not have a large effect upon the molecular weight or the pI of the $\alpha$-chain. For the molecules to have such similar two-dimensional electrophoretic patterns, the changes between them are probably minor and most likely involve one or a few amino acid substitutions.

This LFA-1 variation contrasts with the inherited immunodeficiency syndrome involving the partial or complete deficiency of the Mac-1, LFA-1 family of molecules (15-23). Those patients synthesize normal $\alpha$-chain precursor molecules but apparently don't synthesize normal $\beta$-chains and as a consequence few dimers are formed $(24,25)$. In vitro tests show their granulocyte and monocytes have defects in motility, adherence, and phagocytosis. In addition, they have diminished antibody dependent cell-mediated cytotoxicity (ADCC), and natural killer (NK) cell activity, and have subtle T cell abnormalities (26).

MAb that bind specifically to the LFA-1 glycoproteins have established the involvement of these molecules in several immunological events. Monoclonal antibodies directed at LFA-1 block T cell-mediated killing $(1,3,5,27-34)$, NK cell lysis (5, $31-33,35), \operatorname{ADCC}(36,37)$, mitogen and antigen-induced responses (5) and neutrophil adherence processes (38). Anti-LFA1 MAbs interfere with the $\mathbf{M g}^{+2}$-dependent adherence step of killer cell function $(4,27,31,34)$. These findings implicate the LFA-1 molecules as molecules important in adhesion processes between cells of the immune system.

The LFA-1 phenotypic variants we have detected by lack of reactivity with serum E27 might also be candidates to have subtle alterations of their immune responses. Of the variant individuals we have identified, one patient (E27) has the autoimmune disease lupus. The other two individuals are clinically well, and preliminary screening of their cells ability to stimulate and respond in mixed leukocyte reactions and to PHA has provided normal results (data not shown). More detailed studies will be needed before any conclusions can be drawn regarding effects on immune function related to the variant form of LFA-1.

The LFA-1 variant described here may be one of several LFA-1 variants. Since detection of this variant relied upon a serum containing alloantibodies to LFA-1, other LFA-1 variants may be detected by examining serum from other alloimmunized individuals. Separate experiments designed to investigate surface molecules reactive with serum from lupus patients, some of whom had been previously transfused or been pregnant did not reveal antibodies to LFA-1 although many did have antibodies to HLA (unpublished observations). Similarly, normal individuals who had previously been pregnant have not been observed to have antibodies to the LFA-1 molecules. This may indicate that the high level of antibodies to LFA-1 observed in this patient are relatively uncommon. Alternatively repeated immunization or the altered immune regulation of lupus may have contributed to the high levels. Future analysis of the presence of these antibodies in individuals of known LFA-1 phenotype who have received transfusions or been pregnant will help clarify the frequency, amount of LFA-1 antibodies and the diversity of the LFA-1 molecules.

\section{Acknowledgments}

We thank Ms. Esther Avery for expert technical assistance.

These studies have been supported by grants AI-24624, AM-30036, AM-07062, and AM-09174; and the Lupus Foundation of America. Ken D. Pischel is a recipient of an Arthritis Foundation Investigator Award.

\section{References}

1. Sanchez-Madrid, R., A. M. Krensky, C. F. Ware, E. Robbins, J. L. Strominger, S. J. Burakoff, and T. A. Springer. 1982. Three distinct antigens associated with human T lymphocyte-mediated cytolysis; LFA1, LFA-2, and LFA-3. Proc. Natl. Acad. Sci. USA. 79:7489-7493.

2. Sanchez-Madrid, F., J. A. Nagy, E. Robbins, P. Simon, and T. A. Springer. 1983. A human leukocyte differentiation antigen family with distinct $\alpha$-subunits and a common $\beta$-subunit. J. Exp. Med. 158:17851795.

3. Davignon, D., E. Martz, T. Reynolds, K. Kurzinger, and T. A. Springer. 1981. Monoclonal antibody to a novel lymphocyte functionassociated antigen (LFA-1): mechanism of blocking of $T$ lymphocytemediated killing and effects on other T and B lymphocyte functions. $J$. Immunol. 127:590-595.

4. Trowbridge, I. S., and M. B. Omary. 1981. Molecular complexity of leukocyte surface glycoproteins related to the macrophage differentiation antigen Mac-1. J. Exp. Med. 154:1517-1524.

5. Krensky, A. M., F. Sanchez-Madrid, E. Robbins, J. A. Nagy, T. A. Springer, and S. J. Burakoff. 1983. The functional significance distribution and structure of LFA-1, LFA-2 and LFA-3: cell surface antigens associated with CTL-target interactions. J. Immunol. 131:611616.

6. Russ, G. R., A. P. Haddad, B. D. Tait, and A. J. F. d'Apice. 1985. Polymorphism of the complement receptor for C3bi. J. Clin. Invest. 76: 1965-1970.

7. Boyum, A. 1968. Separation of lymphocytes from blood and bone marrow. Scand. J. Clin. Lab. Invest. 21(Suppl.): 77.

8. Julius, M. H., E. Simpson, and L. A. Herzenberg. 1973. A rapid method for the isolation of functional thymus-derived murine lymphocytes. Eur. J. Immunol. 3:645-649.

9. Marlin, S. D., C. C. Morton, D. C. Anderson, and T. A. Springer. 1986. LFA-1 immunodeficiency disease. J. Exp. Med. 164:855-867.

10. Baur, S., E. S. Vitetta, C. J. Sher, I. Schendein, and J. W. Uhr. 1971. Isolation of heavy and light chains of immunoglobulin from the surfaces of lymphoid cells. J. Immunol. 106:1133-1135. 
11. Pischel, K. D., H. G. Bluestein, and V. L. Woods Jr. 1986. Very late activation antigens (VLA) are human leukocyte-neuronal crossreactive cell surface antigens. J. Exp. Med. 164:393-406.

12. Sanchez-Madrid, F., P. Simon, S. Thompson, and T. A. Springer. 1983. Mapping of antigenic and functional epitopes on the alpha and beta subunits of two related glycoproteins involved in cell interactions, LFA-1 and Mac-1. J. Exp. Med. 158:586-602.

13. Laemmli, U. K. 1970. Cleavage of structural proteins during the assembly of the head of bacteriophage T4. Nature (Lond.). 227:680-685.

14. O'Farrell, P. H. 1975. High resolution two-dimensional electrophoresis of proteins. J. Biol. Chem. 250:4007-4021.

15. Arnaout, M. A., J. Pitt, H. J. Cohen, J. Melamed, F. S. Rosen, and H. R. Colten. 1982. Deficiency of a granulocyte-membrane glycoprotein (gp150) in a boy with recurrent bacterial infections. $N$. Engl. J. Med. 306:693-699.

16. Dana, N., R. F. Todd III, J. Pitt, T. A. Springer, and M. A. Arnauot. 1984. Deficiency of a surface membrane glycoprotein (Mol) in man. J. Clin. Invest. 73:153-159.

17. Crowley, C. A., J. T. Curnutte, R. E. Rosin, J. Andre-Schwartz, J. I. Galin, M. Klempner, R. Synderman, F. S. Southwick, T. P. Stossel, and B. M. Babior. 1980. An inherited abnormality of neutrophil adhesion. Its genetic transmission and its association with a missing protein. $N$. Engl. J. Med. 302:1163-1168.

18. Todd, R. F. III, M. A. Arnaout, R. E. Rosin, C. A. Growley, W. A. Peters, and B. M. Babior. 1984. Subcellular localization of the large subunit of $\mathrm{Mol}$ (Mol; formerly gp 1 10), a surface glycoprotein associated with neutrophil adhesion. J. Clin. Invest. 74:1280-1290.

19. Abramson, J. S., E. L. Mills, M. K. Sawyer, W. R. Regelmann, J. D. Nelson, and P. G. Quie. 1981. Recurrent infections and delayed separation of the umbilical cord in an infant with abnormal phagocytic cell locomotion and oxidative response during particle phagocytosis. $J$. Pediatr. 99:887-894.

20. Bowen, T. J., H. D. Ochs, L. C. Altman, T. H. Price, D. E. Van Epps, D. L. Brautigan, R. E. Rosin, W. D. Perkins, B. M. Babior, S. J. Klebanoff, and R. J. Wedgwood. 1982. Severe recurrent bacterial infections associated with defective adherence and chemotaxis in two patients with neutrophils deficient in a cell-associated glycoprotein. J. Pediatr. 101:932-940.

21. Beatty, P. F., H. D. Ochs, J. M. Harlan, T. H. Price, H. Rosen, R. F. Taylor, J. A. Hansen, and S. J. Klebanoff. 1984. Absence of monoclonal-antibody-in a boy with abnormal leukocyte function. Lancet. i: 535-537.

22. Anderson, D. C., F. C. Schmalstieg, M. A. Arnaout, S. Kohl, M. F. Tosi, N. Dana, F. J. Buffone, B. J. Hughes, B. R. Brinkley, W. D. Dickey, J. S. Abramson, T. A. Springer, L. A. Boxer, J. M. Lollers, and C. W. Smith. 1984. Abnormalities of polymorphonuclear leukocyte function associated with a heritable deficiency of a high molecular weight surface glycoprotein (GP138): common relationship to diminished cell adherence. J. Clin. Invest. 74:536-551.

23. Thompson, R. A., D. C. A. Candy, and A. S. McNeish. 1984. Familial defect of polymorph neutrophil phagocytosis associated with absence of a surface glycoprotein antigen (OKM1). Clin. Exp. Immunol. 58:229-236.

24. Anderson, E. D., F. C. Shearer, K. Becher-Freeman, S. Kohl, C. W. Smith, M. F. Tosi, and T. A. Springer. 1985. Leukocyte LFA-1, OKM1, p150,95 deficiency syndrome: functional and biosynthetic studies in three kindreds. Fed. Proc. 44:2671-2677.
25. Arnaout, M. A., N. Dana, J. Pitt, and R. F. Todd III. 1985. Deficiency of two human leukocyte surface glycoproteins (Mol and LFA1). Fed. Proc. 44:2664-2670.

26. Springer, T. A., W. S. Thompson, L. J. Miller, F. C. Schmalstieg, and D. C. Anderson. 1984. Inherited deficiency of the Mac-1, LFA-1, p150,95 glycoprotein family and its molecular basis. J. Exp. Med. 160: 1901-1918.

27. Davingnon, D., E. Martz, T. Reynolds, K. Kurzinger, and T. A. Springer. 1981. Lymphocyte function-associated antigen 1 (LFA-1): a surface antigen distinct from Lyt-2,3 that participates in T lymphocytemediated killing. Proc. Natl. Acad. Sci. USA. 78:4535-4539.

28. Kurzinger, K., T. Reynolds, R. N. Germain, D. Davignon, E. Martz, and T. A. Springer. 1981. A novel lymphocyte function-associated antigen (LFA-1): cellular distribution, quantitative expression, and structure. J. Immunol. 127:596-602.

29. Sanchez-Madrid, F., D. Davignon, E. Martz, and T. A. Springer. 1982. Antigens involved in mouse cytolytic T-lymphocyte (CTL)-medicated killing: functional screening and topographic relationship. Cell. Immunol. 73:1-11.

30. Sarmieto, M., D. P. Dialynas, D. W. Lancki, K. A. Wall, M. I. Lorber, M. R. Loken, and R. W. Fitch. 1982. Cloned T lymphocytes and monoclonal antibodies as probes for cell surface molecules active in T cell-mediated cytolysis. Immunol. Rev. 68:135-169.

31. Springer, T. A., D. Davignon, M. K. Ho, K. Kurzinger, E. Martz, and $R$. Sanchez-Madrid. 1982. LFA-1 and Lyt-2,3 molecules associated with T lymphocyte-mediated killing; and Mac-1 homologue associated with complement receptor function. Immunol. Rev. 68:111-135.

32. Beatty, P. G., J. A. Ledbetter, P. J. Martin, T. H. Price, and J. A. Hansen. 1983. Definition of a common leukocyte cell-surface antigen (LP95-150) associated with diverse cell-mediated immune functions. $J$. Immunol. 131:2913-2918.

33. Hildreth, J. E. K., F. M. Gotch, P. D. K. Hildreth, and A. J. McMichael. 1983. A human lymphocyte-associated antigen involved in cell-mediated lympholysis. Eur. J. Immunol. 13:202-208.

34. Miedema, F., P. A. Tetteroo, W. G. Hesselink, G. Werner, H. Spits, and C. J. Melief. 1984. Both Fc receptors and lymphocyte function associated antigen-1 on human $\mathrm{T}$ gamma lymphocytes are required for antibody-dependent cellular cytotoxicity (killer-cell activity). Eur. J. Immunol. 14:518-523.

35. Spits, H., G. Keizer, J. Borst, C. Terhorst, A. Hekman, and J. E. deVries. 1983. Characterization of monoclonal antibodies against cell surface molecules associated with cytotoxic activity of natural and activated killer cells and cloned CTL lines. Hybridoma. 2:423-437.

36. Kohl, S., T. A. Springer, F. C. Schmalstieg, L. S. Loo, and D. C. Anderson. 1984. Defective natural killer cytotoxicity and polymorphonuclear leukocyte antibody-dependent cellular cytotoxicity in patients with LFA-1/OKM-1 deficiency. J. Immunol. 133:2972-2978.

37. Bongrand, P., M. Pierres, and P. Godstein. 1983. T-cell mediated cytolysis: on the strength of effector-target cell interaction. Eur. J. Immunol. 13:424-429.

38. Ross, G. D., R. A. Thompsom, M. J. Walport, T. A. Springer, J. V. Watson, R. H. R. Ward, J. Lida, S. J. Newman, R. A. Harrison, and P. J. Lachmann. 1985. Characterization of patients with an increased susceptibility to bacterial infections and a genetic deficiency of leukocyte membrane complement receptor type three $\left(\mathrm{CR}_{3}\right)$ and the related membrane antigen LFA-1. Blood. 66:882-890. 